\title{
Lesiones musculares deportivas: Correlación entre anatomía y estudio por imágenes
}

\author{
Sara Muñoz Ch', Claudia Astudillo A', Edith Miranda V', Juan Francisco Albarracin G $^{2}$.
}

1. Médico Radiólogo. Diagnóstico por Imágenes, Clínica Las Condes. Santiago, Chile.

2. Médico Radiólogo. Hospital San Carlos. San Carlos, Chile.

\section{Muscle injuries in sports: Imaging study}

\begin{abstract}
A large segment of the population participates in sporting activities. Muscle injuries account for approximately one-third of the injuries. The recreational and professional demands of modern society require an early and precise diagnosis of these, for an adequate treatment and follow-up, given the economic and media implications, especially in elite athletes'.

Imaging plays a fundamental role in the evaluation of these lesions. It allows evaluation location, extent, severity and estimations of prognosis, as well as the follow-up to determine the return to sport.

This article reviews the microscopic and macroscopic muscle anatomy, the physiology, types of lesions and their representation in images, both in ultrasound (US) and magnetic resonance (MRI). Different classifications described in the literature are mentioned and a nomenclature and description is proposed, based mainly on the muscle anatomy, localization and type of injury.

Keywords: Muscle tear, Muscle tear classification, Sports-related muscle injury, MRI, US.
\end{abstract}

Resumen. Un gran segmento de la población participa en actividades deportivas. Las lesiones musculares corresponden a aproximadamente un tercio de las lesiones deportivas. Las demandas recreacionales y profesionales de la sociedad moderna exigen un diagnóstico precoz y preciso, para un adecuado tratamiento y seguimiento, dadas las implicancias económicas y mediáticas, especialmente en deportistas de elite. La imagenología tiene un rol fundamental en la evaluación de estas lesiones. Permite evaluar localización, extensión, severidad y estimar pronóstico, así como también el seguimiento para determinar el retorno deportivo.

En este artículo se revisa la anatomía microscópica y macroscópica muscular, la fisiología, los tipos de lesiones y su representación en imágenes, tanto en ultrasonido (US), como en resonancia magnética (RM). Se mencionan distintas clasificaciones descritas en la literatura y se propone una nueva nomenclatura y descripción, basada principalmente en la anatomía muscular, la localización y cuantificación de las lesiones. Palabras clave: Desgarro muscular, Lesión muscular deportiva, Clasificación desgarro muscular.

Muñoz S., et al. Lesiones musculares deportivas: Correlación entre anatomía y estudio por imágenes. Rev Chil Radiol 2018; 24(1): 22-33.

Correspondencia: Sara Muñoz / smunoz@clinicalascondes.cl

Trabajo enviado el 31 de agosto de 2017. Aceptado para publicación el 25 de septiembre de 2017.

\section{Conceptos anatómicos y fisiológicos}

Para la correcta interpretación de los hallazgos, tanto ecográficos como en RM, es fundamental conocer la anatomía microscópica y macroscópica muscular.

El músculo estriado en su conjunto, puede considerarse el órgano más grande del cuerpo. Representa aproximadamente el 25 a $30 \%$ del peso corporal en mujeres y el 40 a $50 \%$ en hombres. Está formado por dos componentes: las fibras musculares y el tejido conjuntivo estromal.
La célula o fibra muscular es el elemento estructural básico. Mide entre 10 - $120 \mu \mathrm{m}$. En su interior existen los sarcómeros donde se encuentran los filamentos de actina y miosina, responsables de la contracción y elongación de los músculos².

Las fibras musculares individuales se agrupan en haces llamados fascículos, que a su vez se agrupan para formar los músculos. Varían en longitud y diámetro transversal dependiendo de cada músculo y tienden a ser de tamaño parecido dentro de un músculo dado. 
El tejido conectivo proporciona el armazón para mantener la forma del músculo tanto en estado relajado como contraído.

Cada fibra muscular está rodeada por una delicada red de tejido conectivo, el endomisio, que contiene pequeños vasos, nervios y matriz de proteoglicanos para el intercambio iónico y metabólico.

Varias fibras musculares forman un fascículo que se rodea de un tejido conectivo más grueso, el perimisio que también proporciona vascularización, inervación y matriz.

Varios fascículos forman un músculo rodeado por una capa externa de tejido conectivo, el epimisio ${ }^{3}$ (Figura 1).

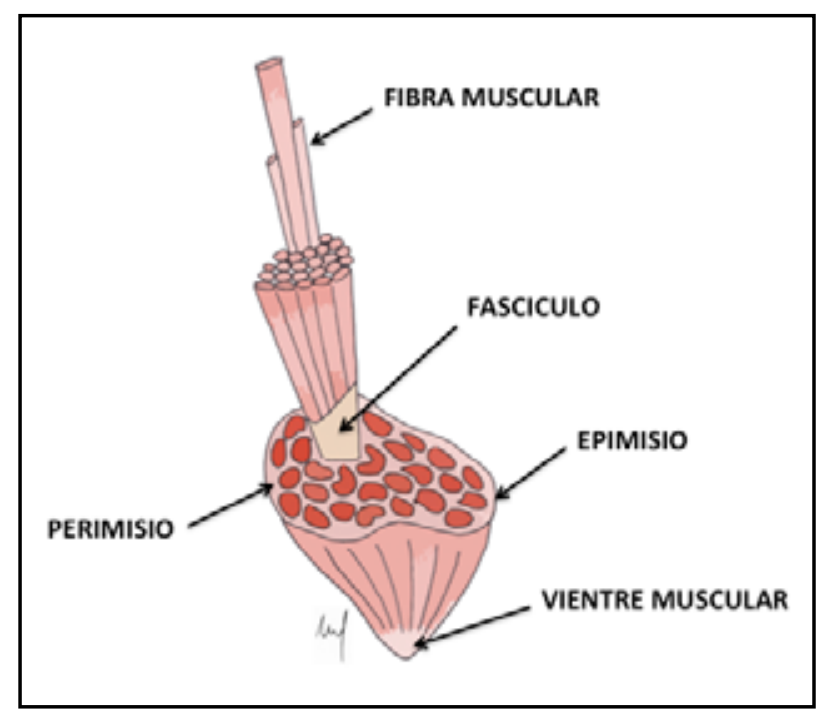

Figura 1. Esquema de la anatomía microscópica y del tejido conectivo del músculo estriado.

Las fibras musculares se insertan en diferentes componentes del tejido conectivo, incluyendo la aponeurosis, los tabiques aponeuróticos intramusculares (tendones centrales) o directamente en el tendón. La disposición interna varía de acuerdo a la orientación de los fascículos, lo que determina la forma y función del músculo:

- Cuando los fascículos se orientan en forma paralela a la línea de tracción se produce un alto grado de acortamiento y gran velocidad de movimiento, sin embargo, la fuerza es escasa. Ejemplos de estos músculos son los acintados como el sartorio o el recto abdominal.

- Cuando los fascículos se orientan en forma oblicua en relación a la línea de tracción, hay una mayor superficie de inserción, lo que biomecánicamente genera mayor fuerza con menor rango de movimiento ${ }^{4}$ (Figura 2).

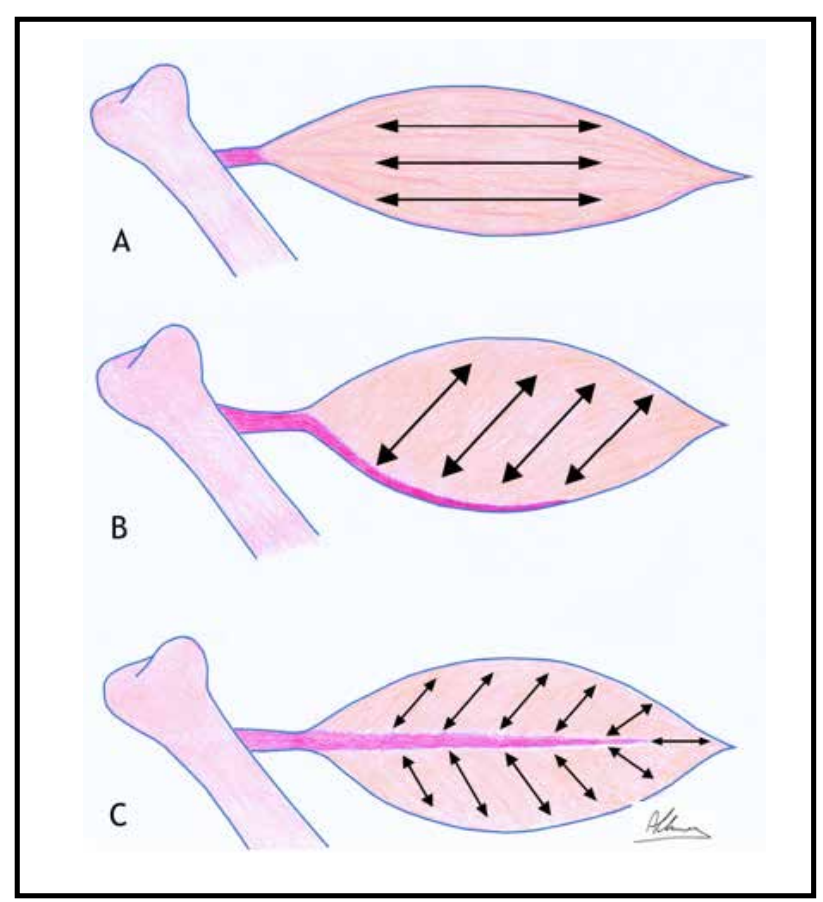

Figura 2. Esquema de la fuerza muscular en relación a la orientación fascicular (flechas): $A$. Músculo fusiforme, $B$. Músculo unipenado, C. Músculo bipenado.

La orientación oblicua de los fascículos es propia de los músculos peniformes (Del latín penna: pluma y forma: forma). Existen varios tipos de músculos peniformes: (Figura 3).

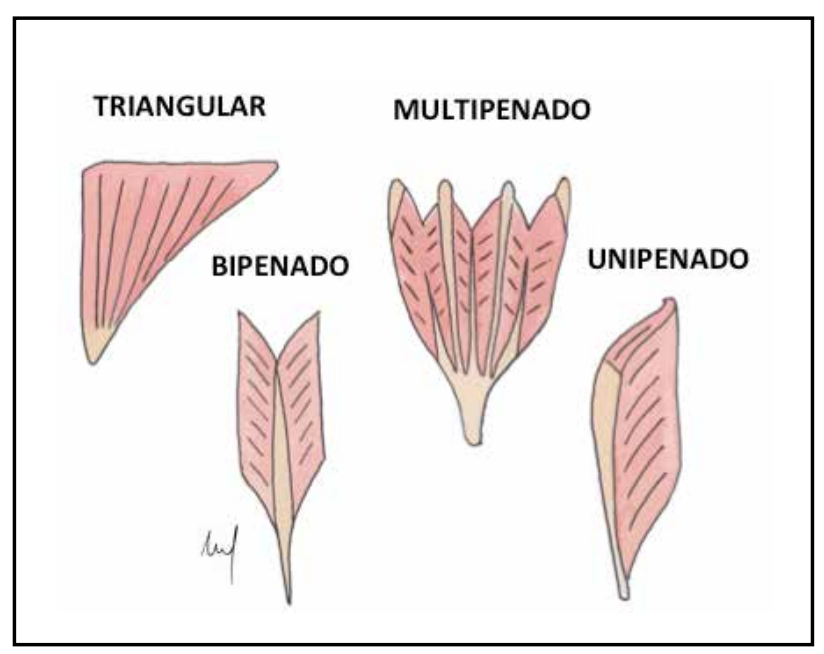

Figura 3. Esquema de músculos peniformes.

En los músculos bipeniformes los fascículos convergen en un tendón central único, mientras que los multipeniformes tienen más de un tendón. Los fascículos también pueden adoptar una disposición espiral en músculos que se curvan o tienen recorrido espiral como el supinador o el pectoral mayor (Figura 4). 


\section{ESPIROIDEO}

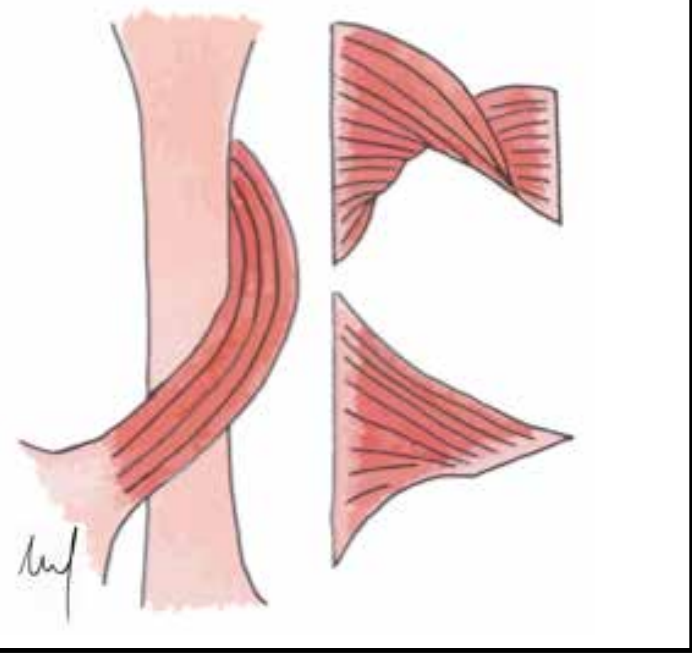

Figura 4. Esquema de músculos espiroídeos.

Por otro lado, los músculos pueden tener un solo vientre o estar formados por la unión de dos o tres cabezas como el bíceps braquial o tríceps, que se unen en un tendón distal ${ }^{5}$.

Desde el punto de vista histológico existen dos tipos de fibras musculares:

- Tipo I o de contracción lenta: tienen un diámetro más pequeño, más mitocondrias, mioglobina y capilares por fibra, más adecuadas para contracción repetitiva, con mayor resistencia a la fatiga.

- Tipo Il o de contracción rápida: de mayor tamaño, con menos vasos sanguíneos y mioglobina, más adecuadas para fuerzas rápidas fásicas, mejor adaptadas para actividad intensa de corta duración y mayor tensión ${ }^{6}$.

La tensión activa que produce un músculo es proporcional al tipo de fibras que contiene, por lo cual, músculos con alta proporción de fibras tipo II son capaces de generar mayor fuerza.

Los ejercicios de baja intensidad involucran selectivamente fibras tipo I, mientras que las fibras tipo II son reclutadas cuando la intensidad del ejercicio aumenta.

Los velocistas, por ejemplo, tienen predominancia de fibras tipo II, mientras que en los maratonistas predominan del tipo I. No está claro si esta predominancia está determinada genéticamente o si es una respuesta al entrenamiento.

Los desgarros musculares son más frecuentes en músculos con predominancia de fibras tipo $\|^{7,8}$.

Cada músculo está constituido por una mezcla de ambos tipos de fibras. En algunos predominan las tipo II (ejemplo: gemelo medial) y en otros las tipo I (ejemplo: sóleo).
Durante la contracción muscular la fuerza se transmite al esqueleto desde el tendón, generando tres tipos de efecto ${ }^{3,4}$ (Figura 5):

a. Contracción isométrica: el músculo se contrae, pero no cambia su longitud.

b. Contracción isotónica: el músculo se contrae y se acorta.

c. Contracción excéntrica: el músculo se contrae y al mismo tiempo se alarga.

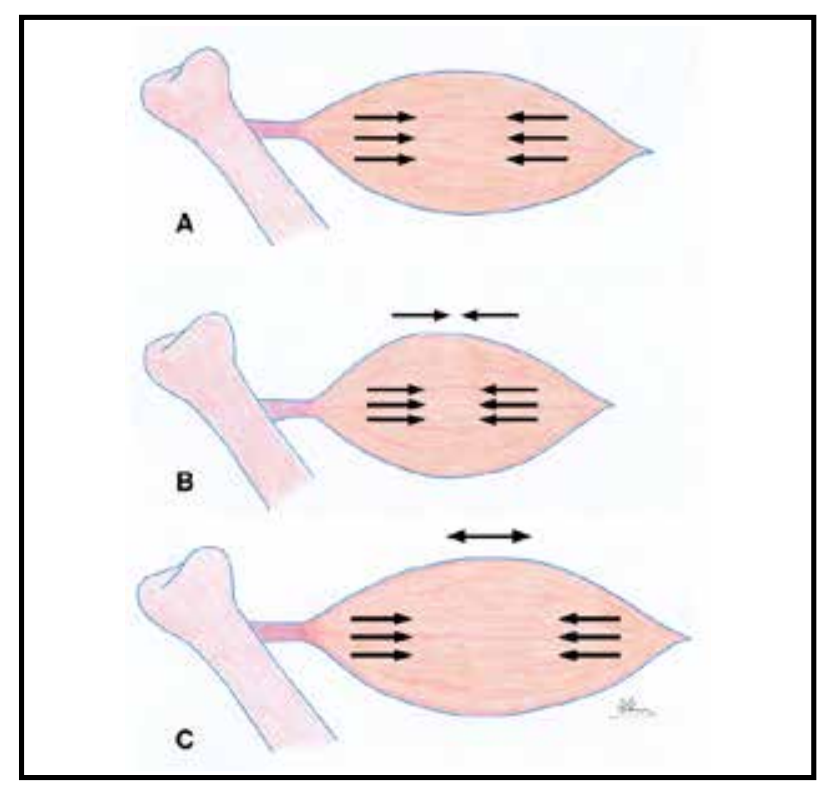

Figura 5. Esquema de tipos de contracción muscular: A. Contracción isométrica. B. Contracción isotónica. C. Contracción excéntrica.

Un desgarro se produce cuando la tensión excede la fuerza del elemento estructural más débil. Se ha demostrado experimentalmente que el músculo estirado hasta la falla, se rompe siempre cerca de la unión músculo tendínea distal ${ }^{9}$.

Esta introducción anatómica es relevante, porque los desgarros musculares ocurren predominantemente en músculos biarticulares (que cruzan más de una articulación), de acción excéntrica, con alta proporción de fibras tipo II, en zonas de transición anatómica o funcional, que corresponden a la inserción de los fascículos en las fascias, aponeurosis o tendones, ya sean centrales o distales, ya que estos sitios generan la mayor concentración de fuerzas intrínsecas, por lo que son los puntos de mayor debilidad biomecánica ${ }^{10}$.

El movimiento es el resultado de la contracción muscular, donde un grupo muscular realiza la función predominante. Otros músculos, llamados sinérgicos, actúan en el mismo sentido del movimiento, apoyando al grupo principal. Los antagonistas son los que se oponen a la acción ${ }^{3}$. Para la contracción correcta de un músculo se requiere que otro se relaje, permitiendo el 
movimiento normal esperado. Si el músculo principal se contrae desproporcionadamente en relación a su antagonista, no soportará la tracción y se romperá durante la contracción. Así, un entrenamiento óptimo que corrija y mejore la coordinación muscular, que incluya trabajo de fuerza y resistencia, es fundamental para reducir la incidencia de estas lesiones.

\section{Métodos de estudio de las lesiones musculares Estudio con Rayos $X$}

La radiografía simple tiene un rol limitado porque la musculatura no tiene una buena representación en ella. Puede ser útil para detectar calcificaciones o si en la evolución de una lesión muscular se sospecha miositis osificante.

La tomografía computada no está indicada para la evaluación de desgarros. Puede ser útil para diferenciar si calcificaciones son musculares o están en contacto con la cortical ósea.

La RM y el US son los exámenes de elección ${ }^{11,12,13,14 ;}$ la decisión de cual utilizar depende de la experiencia del radiólogo y de la disponibilidad de equipamiento apropiado.

En nuestro medio, el US es la mejor técnica de exploración en la gran mayoría de los casos.

\section{Estudio con RM}

La RM es reproducible, con capacidad multiplanar, alto contraste tisular, alta sensibilidad, menor especificidad, con la ventaja de explorar zonas extensas en una sola imagen. Es de mayor costo y menor disponibilidad que el US.

En lesiones muy sutiles o muy extensas, la RM puede tener un mejor rendimiento.

Los estudios en RM frente a la sospecha de lesiones musculares deben incluir secuencias potenciadas en T1, T2, densidad protónica con saturación de la grasa (DP FS) y STIR. Deben realizarse planos axial, coronal y sagital. Recomendamos el estudio abarcando toda la extensión del grupo muscular comprometido.

\section{Estudio con US}

EI US es un examen en tiempo real, que permite hacer el diagnóstico en forma inmediata, es dinámico y eventualmente comparativo. Es de menor costo que la RM, con mayor disponibilidad en nuestro medio y puede servir como apoyo para procedimientos intervencionales, como aspiración del hematoma e inyección de PRP (plasma rico en plaquetas). Los inconvenientes del US se relacionan con el pequeño campo visual, la necesidad de un operador experto y que es un examen no reproducible.

La elección del transductor depende del tamaño y profundidad del músculo o grupo muscular a examinar. Elegir entre 7-12 MHz es apropiado para la mayoría de los casos, sin embargo, la definición puede ser insuficiente para músculos pequeños. Así mismo, en pacientes muy voluminosos o con hipertrofia de la musculatura, puede ser necesario utilizar transductores de menor frecuencia.

El examen debe realizarse en el eje corto y largo de cada músculo.

La ecoestructura de un músculo consta de un fondo hipoecogénico que refleja los fascículos musculares y bandas hiperecogénicas lineales delimitadas que representan tabiques fibroadiposos, el perimisio. Las aponeurosis y tendones intramusculares aparecen como bandas hiperecogénicas que se visualizan mejor en el eje corto del músculo ${ }^{4,5}$. La distribución entre estos componentes traduce la proporción entre fascículos musculares y tejido conjuntivo. El US es capaz de reconocer la arquitectura interna de los músculos y de ahí la importancia de conocer la anatomía del músculo estudiado.

En el plano transverso, eje corto, el aspecto ecográfico del músculo se ha descrito como "noche estrellada" por la visualización de puntos hiperecogénicos (perimisio) en un fondo hipoecogénico (fascículos musculares) (Figura $6 \mathrm{a}, \mathrm{b}$ ).
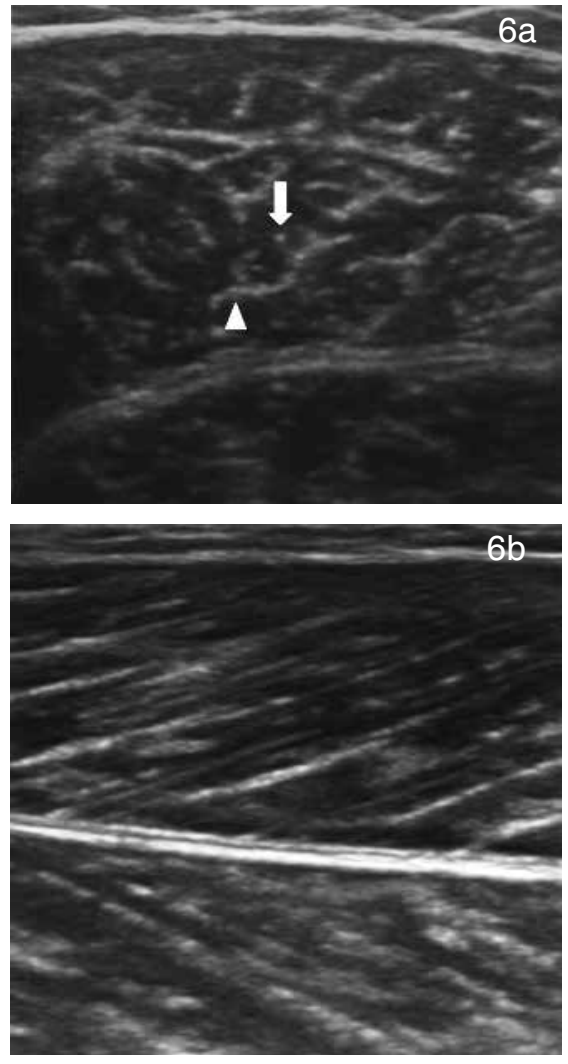

Figura 6. US de la ecoestructura muscular normal: Perimisio (flecha). Tendón central (cabeza de flecha). a) Corte transversal. b) Corte longitudinal.

El ángulo entre el haz de US y el músculo es fundamental. Un ángulo que se desvía de la perpendicular hace que el músculo se vea hipo o hiperecogénico como artefacto (Anisotropía) ${ }^{4}$.

La semiología ecográfica de las lesiones musculares es limitada, lo que hace indispensable la correlación clínica para una correcta interpretación de los hallazgos. 
En prácticamente todas las lesiones veremos uno o más los siguientes signos:

- Aumento o disminución difusa de la ecogenicidad: dependiendo del momento de la exploración en relación al evento traumático, puede traducir lesión fibrilar microscópica, edema, sangrado reciente o proceso inflamatorio.

- Distorsión de la arquitectura o patrón fascicular: corresponde a la distorsión o pérdida del aspecto peniforme.

- Solución de continuidad: traduce interrupción macroscópica de fascículos. Es una avulsión y retracción de fibras musculares en relación al tendón o aponeurosis donde se inserta, ya sea central intramuscular, periférica o distal.

- Colección líquida: que corresponde al hematoma.

\section{Tipos de lesiones musculares deportivas}

Según su mecanismo se han clasificado en:

A. Intrínsecas o indirectas: no actúa una fuerza externa.

B. Extrínsecas o directas: la causa es una fuerza externa.

\section{A. Lesiones intrínsecas o indirectas \\ i) Desgarros}

Corresponden a un espectro de lesiones que van desde la lesión fibrilar microscópica mínima, en que no se identifica un defecto macroscópico, hasta la rotura completa de un vientre muscular.

Ocurren por estiramiento excesivo o simultáneo a una contracción excéntrica brusca. Hay daño estructural del tejido muscular, rotura de fibras $y / o$ fascículos. El mecanismo más frecuente es una elongación brusca al momento de la contracción excéntrica, que es común en deportes que implican aceleración-desaceleración o cambios súbitos de dirección.

A través de los años se han descrito distintas clasificaciones de las lesiones musculares en la literatura, tanto para US como para RM, la mayoría utilizando grados desde el 0 al 4, dependiendo del autor. Ninguna ha sido aceptada universalmente. A continuación, se mencionan las más utilizadas ${ }^{10,15}$ (Tabla 1).

En 2012 se realizó una reunión de expertos internacionales en medicina deportiva, para desarrollar definiciones prácticas y científicas de las lesiones musculares, así como un nuevo sistema de clasificación. Se le conoce como el Consenso de Munich ${ }^{10}$, (Nivel de evidencia V. Opinión de expertos), cuya sugerencia se resume en la Tabla 2.

Tabla 1. Distintas clasificaciones de lesiones musculares.

\begin{tabular}{|l|r|l|}
\hline Autor & Año & Método \\
\hline & & \\
O' Donoghue & 1962 & - \\
Ryan & 1969 & Descrita para cuadriceps \\
Takebayashi & 1995 & US \\
Petrons & 2002 & US \\
Stoller & 2007 & RM \\
Consenso de Munich & 2012 & US-RM \\
Pollock & 2015 & RM \\
\hline
\end{tabular}

Tabla 2. Resumen de clasificación de lesiones musculares agudas según el Consenso de Munich.

\begin{tabular}{|c|c|c|c|}
\hline \multirow[t]{2}{*}{ A. Indirectas } & $\begin{array}{l}\text { Trastorno muscular } \\
\text { funcional }\end{array}$ & $\begin{array}{l}\text { Tipo 1: Trastorno relacionado } \\
\text { con esfuerzo excesivo } \\
\text { Tipo 2: Trastorno neuromuscular }\end{array}$ & $\begin{array}{l}\text { Tipo 1A: Inducido por fatiga } \\
\text { Tipo 1B: DOMS } \\
\text { Tipo 2A: Relacionado con la } \\
\text { médula espinal } \\
\text { Tipo 2B: Relacionado con el } \\
\text { músculo }\end{array}$ \\
\hline & $\begin{array}{l}\text { Lesión muscular } \\
\text { estructural }\end{array}$ & $\begin{array}{l}\text { Tipo 3: Rotura muscular parcial } \\
\text { Tipo 4: Rotura total o subtotal }\end{array}$ & $\begin{array}{l}\text { Tipo 3A: Desgarro parcial } \\
\text { menor } \\
\text { Tipo 3B: Desgarro parcial } \\
\text { moderado } \\
\text { Rotura total o subtotal } \\
(>50 \%) \\
\text { Avulsión tendinosa }\end{array}$ \\
\hline B. Directas & $\begin{array}{l}\text { Contusión } \\
\text { Laceración }\end{array}$ & & \\
\hline
\end{tabular}


Esta clasificación incluye los trastornos neuromusculares (tipo 2), los que se apartan del interés de este artículo.

Según nuestra experiencia, ninguna clasificación logra responder a cabalidad la información necesaria para el manejo clínico de las lesiones musculares deportivas. En nuestra opinión, una exhaustiva descripción de la alteración y de su localización es de mayor utilidad que una clasificación en grados, como se discutirá más adelante.

Se revisa a continuación el aspecto imagenológico de las lesiones musculares indirectas tipo 1, 3, 4 y de las lesiones directas (en clasificación Munich).

La gran mayoría de los pacientes que vemos en la práctica radiológica, ya sea deportistas aficionados o profesionales, corresponden a lesiones tipo 3.

Para interpretar el aspecto imagenológico de las lesiones es necesario recordar que las fibras musculares son microscópicas, de manera que una lesión "fibrilar" no tiene representación como un defecto o gap en el tejido muscular. Las fibras se organizan en fascículos que miden entre $2 y$ $5 \mathrm{~mm}$, que sí pueden visualizarse imagenológicamente.

De esta manera, se llamará desgarro parcial menor ( $3 A$ o "fibrilar") al que compromete un diámetro menor que un fascículo, y desgarro parcial moderado (3B o "fascicular") al que compromete más de un fascículo.

El US y la RM no siempre determinan con exactitud el tamaño del defecto, y pueden sobreestimar el daño por el edema en US y el aumento de señal en $\mathrm{RM}^{11}$.

En ocasiones encontramos pacientes con examen clínico positivo, en que los hallazgos imagenológicos son negativos. En estos casos, el paciente ha sufrido una "contractura", terminología que el acuerdo de Munich no recomienda utilizar. Correspondería a un trastorno funcional relacionado con esfuerzo excesivo inducido por fatiga o lesión tipo $1 \mathrm{~A}$ en acuerdo de Munich. No hay daño estructural del músculo. Hay dolor y palpación dolorosa de una zona extensa, abarcando un grupo muscular.

\section{Desgarro "fibrilar" (o parcial menor $3 A$ en acuerdo de Munich)}

Corresponde a la lesión fibrilar mínima. Produce leve disconfort al momento de la lesión. Hay dolor a la elongación pasiva del músculo y dolor focal a la palpación.

No hay un defecto en el músculo. Produce distorsión de la arquitectura, edema y/o hemorragia en la zona de la lesión, en áreas de transición anatómica.

Hay que tener en cuenta que, en lesiones pequeñas, las manifestaciones ecográficas pueden tardar horas en aparecer, de manera que el estudio con US no debe realizarse inmediatamente después del evento traumáti$\mathrm{co}$, ya que puede ser negativo. En casos de clínica focal positiva y estudio US negativo, recomendamos reevaluar luego de 24 horas.

Desde el punto de vista ecográfico puede haber aumento o disminución focal de la ecogenicidad, asociado o no a distorsión de la arquitectura y del patrón fascicular normal (Figura $7 \mathrm{a}, \mathrm{b}, \mathrm{c}$ ).

En RM la lesión fibrilar se observa como aumento de señal en secuencias sensibles al líquido, sin colección líquida, sin defecto macroscópico (Figura $8 \mathrm{a}, \mathrm{b}$ ).

No siempre es fácil cuantificar el tamaño de la lesión. Nuestra recomendación para ambos métodos es medir las dimensiones de la alteración en el eje corto y largo. Estas lesiones curan por lo general ad integrum, sin formación de cicatriz fibrosa.
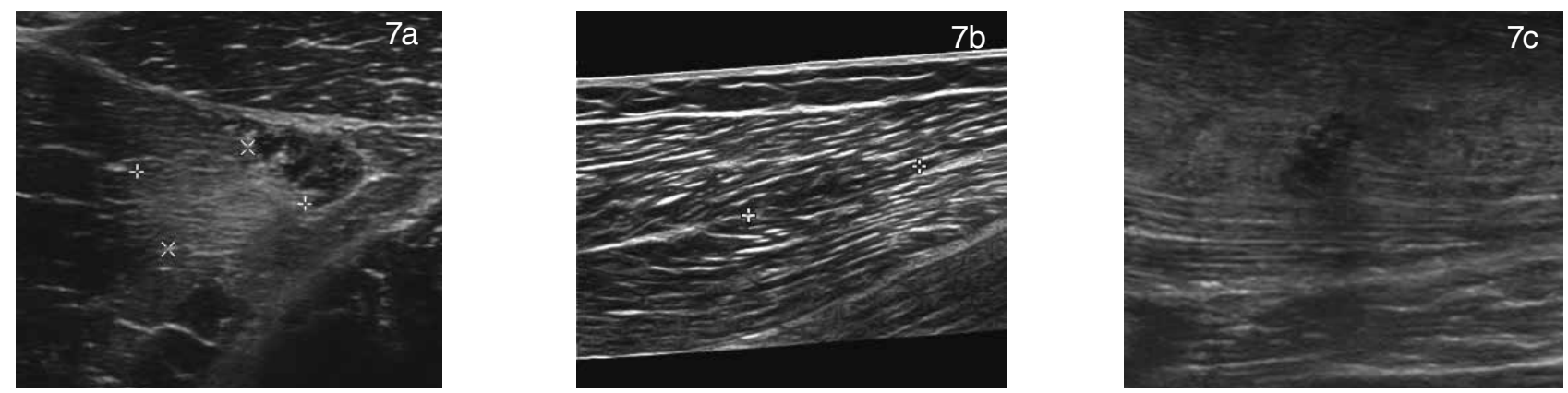

Figura 7. Lesión fibrilar en US: a) Aumento focal de ecogenicidad con medida en eje corto (cruz). b) Disminución focal de ecogenicidad en eje largo (cruz). c) Distorsión de la arquitectura muscular.
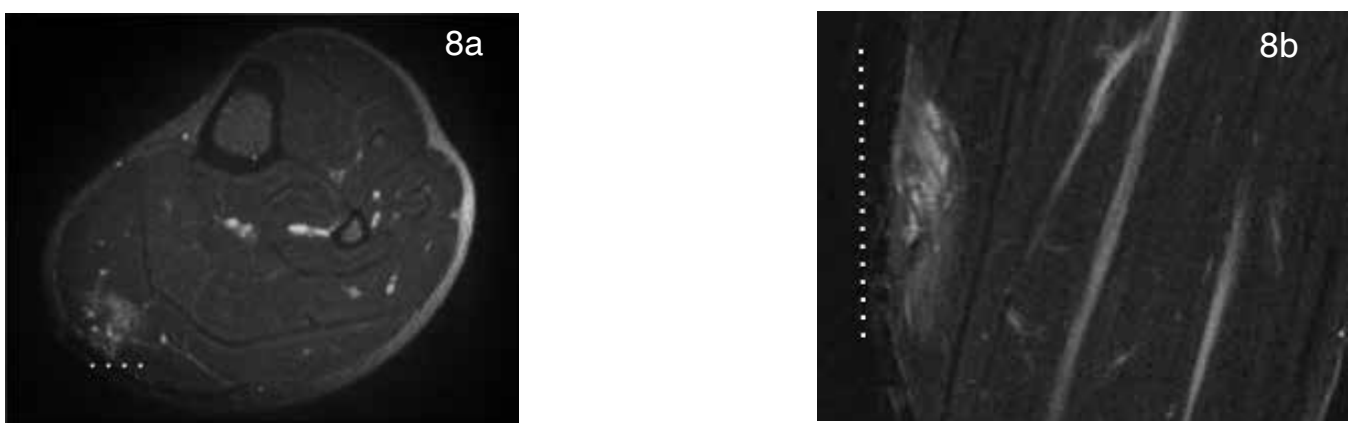

Figura 8. Lesión fibrilar en RM. a) DP FS axial con medida en eje corto (línea de puntos). b) DPFS coronal con medida en eje largo. 


\section{Desgarro parcial "fascicular" (moderado 3B en acuerdo de Munich)}

Corresponde a la lesión parcial con compromiso de fascículos musculares que son visibles macroscópicamente. Produce dolor intenso al momento de la lesión, dolor local a la palpación y a la elongación pasiva. El deportista debe detener la actividad. Se pierde la contractilidad local. Hay compromiso de fascículos y del tejido conectivo adyacente (endomisio y perimisio), lo que ayuda a diferenciarlas de la lesión fibrilar.

Se visualizará disrupción de fibras, posible retracción de ellas y hematoma.

Teniendo en cuenta que el flujo sanguíneo se encuentra aumentado cuando el músculo está en actividad, estas lesiones producen sangrado rápidamente. Esta hemorragia tiene diferentes maneras de presentarse, dependiendo de la integridad de la fascia. Si está indemne, el hematoma queda confinado al músculo. Si la fascia está rota, el hematoma se acumula en el espacio intermuscular o subcutáneo. Este es el caso en que los pacientes se presentan con equímosis.

El hematoma es el sello de la rotura muscular y su aspecto en US depende de la localización de la lesión y del tiempo transcurrido.

En la hemorragia aguda o reciente suele ser ecogénico (Figura 9a). A las pocas horas se comporta como una colección hipoecogénica y homogénea (Figura 9b), aspecto que permanece por tiempo variable dependiendo, entre otras cosas, de su tamaño. En etapa más crónica, los elementos de la sangre, células, suero, fibrina etc., pueden separarse y dar como resultado un nivel líquidolíquido. Después de unos días, la colección se hace uniforme, anecogénica, lo que se llama hematoma en etapa "serosa" (Figura 9c).

Para la estimación del tamaño de la lesión, que a veces puede ser variable y difícil, se sugiere lo siguiente:

- Si el desgarro ocurre en la unión miotendínea o mioaponeurótica central, recomendamos la medición lineal del hematoma en el eje corto y largo del músculo (Figura 10a y 10b). Sus dimensiones por lo general coinciden con la magnitud del daño.

- Si el desgarro ocurre en la unión de las fibras a la fascia (miofascial periférico), sin rotura de la fascia, recomendamos la medición curva en el eje corto en la periferia del músculo (Figura 11a) y la medición en el eje largo, también en la periferia (Figura 11b). Habitualmente las dimensiones del hematoma coinciden con la envergadura de la lesión.

- Si el desgarro se sitúa miofascial periférico con rotura de la fascia muscular, el hematoma no queda contenido dentro del músculo y se acumula en el espacio intermuscular. En esta situación es más difícil estimar la cuantía del daño, por cuanto el tamaño del hematoma no necesariamente coincide con la envergadura de la lesión. Recomendamos la estimación del desgarro en el eje corto y largo, y la medición del hematoma intermuscular por separado (Figura 12).

En US y RM se utilizan los mismos criterios de cuantificación de las lesiones. La desventaja de la RM es que a veces puede ser difícil diferenciar el edema del hematoma ya que ambos en ocasiones pueden verse similar (Figura 13).
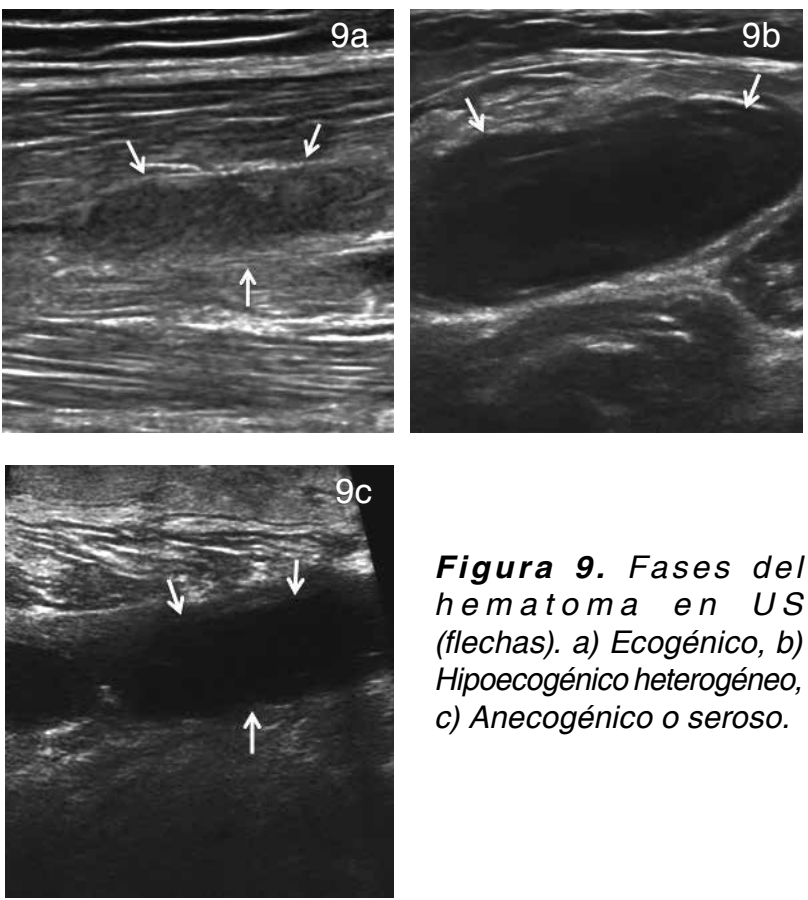

Figura 9. Fases del hematoma en US (flechas). a) Ecogénico, b) Hipoecogénico heterogéneo, c) Anecogénico o seroso.
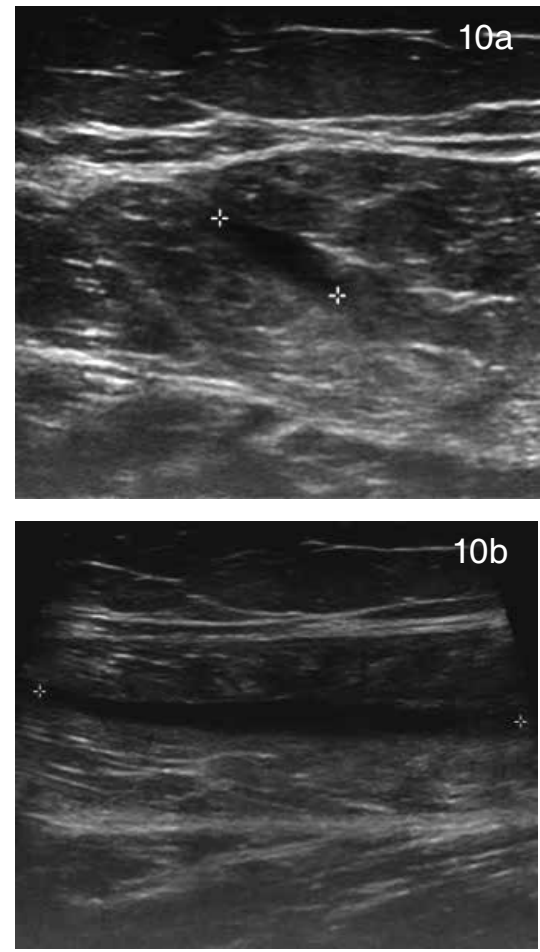

Figura 10. Desgarro fascicular miotendíneo o mioaponeurótico central con medición (cruz) en US. a) Eje corto, b) Eje largo. 

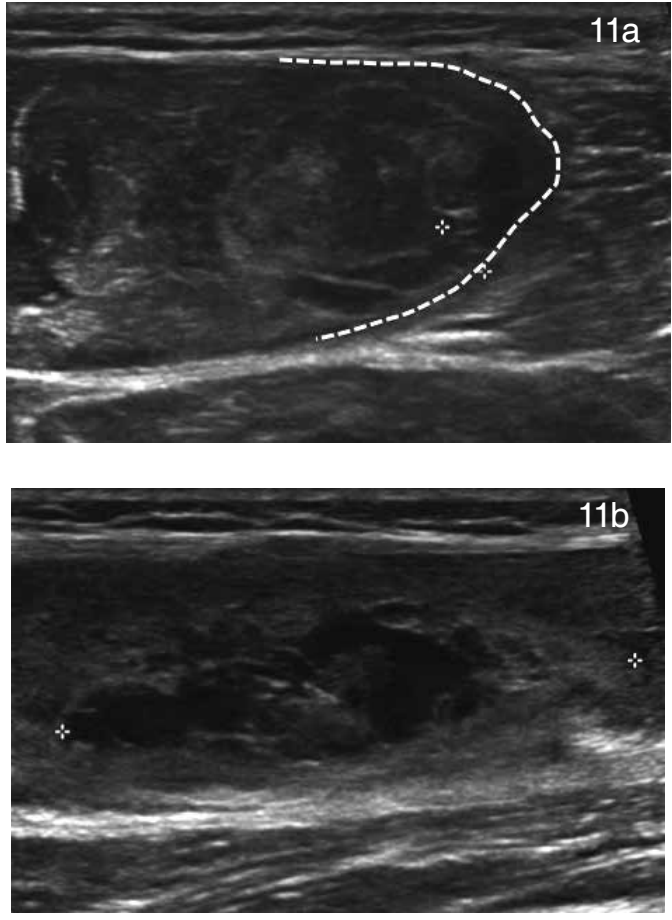

Figura 11. Desgarro fascicular en localización miofascial periférico, sin rotura de la fascia en US. a) Eje corto, distorsión y disrupción de fibras, defectos y retracción parciales, con medición curva de la extensión circunferencial del compromiso muscular (línea de puntos). b) Eje largo, medición longitudinal (cruz) del defecto muscular con hematoma.
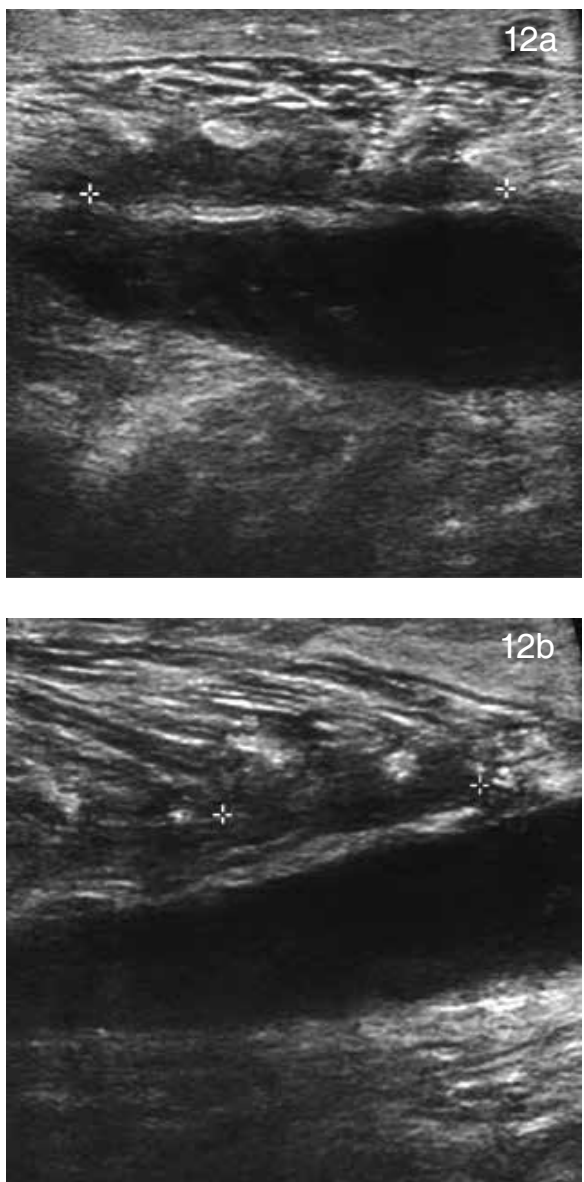
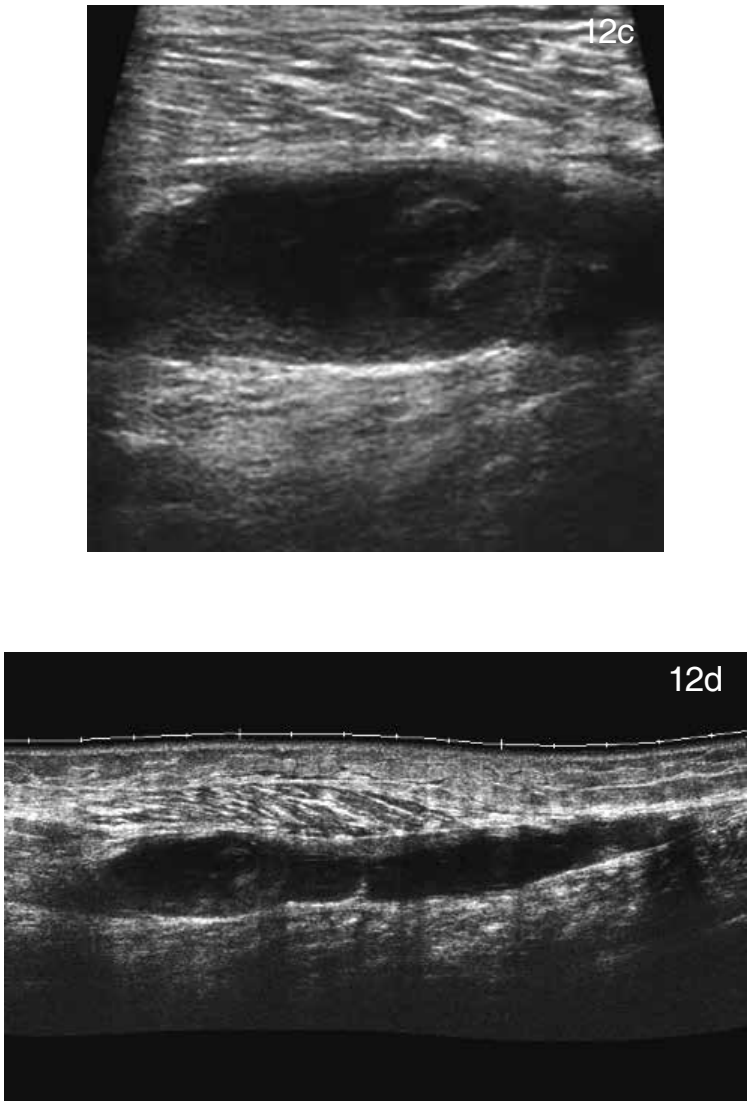

Figura 12. Desgarro fascicular en localización miofascial periférico, con rotura de la fascia y hematoma intermuscular en US. a) Eje corto del desgarro con medida (cruz), b) Eje largo del desgarro con medida (cruz), c) Eje corto del hematoma, d) Eje largo del hematoma en visión extendida.

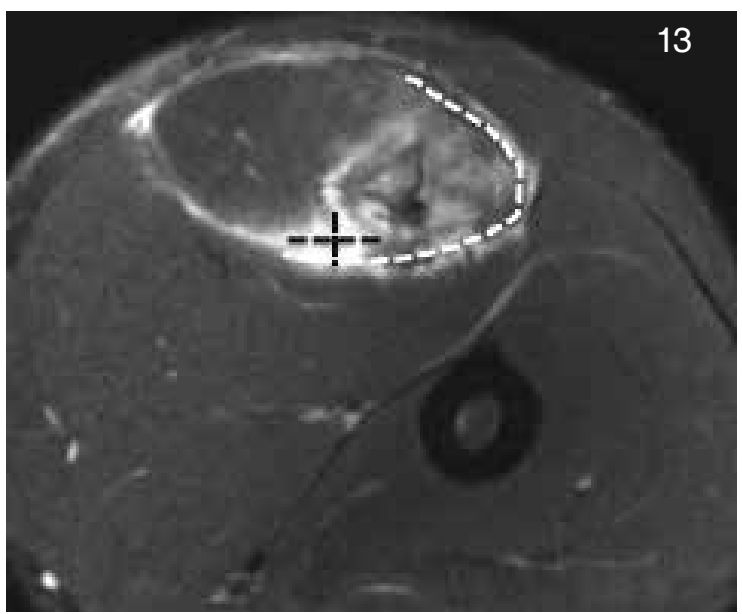

Figura 13. Desgarro fascicular en localización miofascial periférico, con edema, pero sin rotura de la fascia en RM axial DP FS. Medición curva de la extensión circunferencial del compromiso muscular (líneas blancas). Medición del defecto muscular con hematoma (líneas negras). 


\section{Desgarro total-subtotal (o tipo 4 en acuerdo de Munich)}

La rotura completa de un vientre muscular es rara. Las roturas subtotales, que comprometen más del $50 \%$ y las avulsiones son más frecuentes.

La experiencia clínica ha demostrado que el tiempo de curación de las roturas subtotales y de las totales es similar.

Se incluyen en esta categoría las avulsiones, ya que biomecánicamente corresponden a una rotura completa del origen de inserción. Los sitios más frecuentes son la inserción proximal del recto femoral, isquiotibiales, aductor largo e inserción distal del semitendinoso.

El paciente se presenta con severo dolor y pérdida de la función, con un defecto palpable y equimosis.

En US el examen puede ser dificultoso por la limitación del campo visual. Hay solución de continuidad que compromete todo el espesor del músculo y colección líquida interpuesta entre los cabos de la rotura.

En RM es relativamente más fácil valorar el tamaño del defecto y del hematoma.

\section{ii) DOMS (Tipo 1B en acuerdo de Munich)}

De la sigla en inglés Delayed Onset Muscle Soreness ${ }^{16}$, el "dolor muscular de comienzo tardío" fue descrito a comienzos de siglo y su definición inicial no se ha modificado significativamente. Su etiopatogenia no ha sido aclarada. Se estima que prácticamente toda persona adulta ha experimentado alguna vez dolor muscular de aparición tardía.

Se da en deportistas principiantes o atletas que realizan actividades excéntricas. El cuadro consiste en la aparición de dolor muscular horas después de un ejercicio extenuante o no acostumbrado, que dura 5 a 7 días y que es autolimitado. El peak es a los 2 o 3 días después del ejercicio. Hay dolor inflamatorio agudo característico, debido a la liberación local de mediadores inflamatorios.

En US se observa aumento de volumen del músculo afectado asociado a aumento difuso de la ecogenicidad por edema (Figura 14), lo cual también se puede ver en RM.

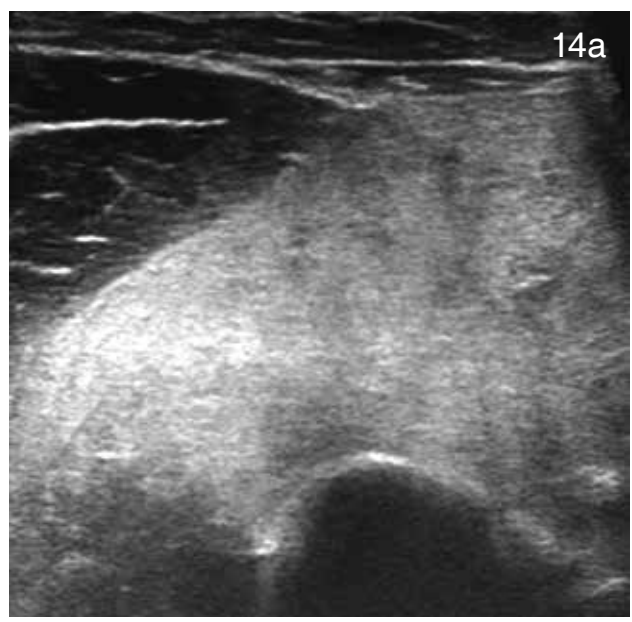

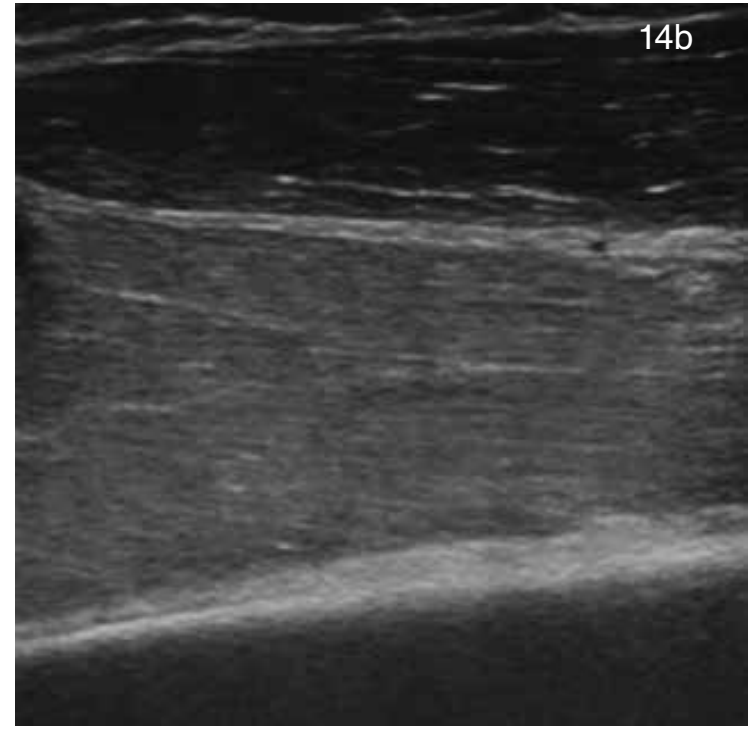

Figura 14. DOMS en US. Edema muscular con marcado aumento de ecogenicidad y volumen del músculo afectado, sin alteración de la arquitectura muscular. a) Eje corto, b) Eje largo.

\section{B. Lesiones extrínsecas o directas}

Contusión-Laceración (Tipo B en acuerdo de Munich)

La contusión muscular corresponde a una compresión del músculo por un traumatismo directo. Resulta del choque de la masa muscular contra una superficie dura y el hueso, son frecuentes en deportes de contacto como el rugby, fútbol, etc. Su severidad depende de la fuerza de contacto y la situación de contracción del músculo al momento del trauma. Afecta generalmente a músculos en situación profunda, vecinos al plano óseo, como el vasto intermedio en el muslo. Provoca sangrado que precozmente produce un aspecto hiperecogénico difuso de la zona, transformándose en el tiempo en un área mixta hipoecogénica con progresiva mejor delimitación. Se pierde el patrón fibrilar normal. Puede afectar a más de un músculo. Tanto en US como en RM hay edema, hemorragia, solución de continuidad, distorsión de la arquitectura y colección líquida - hematoma.

La laceración resulta de lesiones penetrantes y se ve en deportes como ski acuático, motociclismo, etc. Se acompaña de solución de continuidad en la piel y afecta más frecuénteme a músculos superficiales.

Por lo tanto, a partir de nuestra experiencia y considerando las clasificaciones descritas en la literatura, proponemos la siguiente descripción imagenológica de las lesiones musculares deportivas, basada en la anatomía muscular, la localización y el tipo de lesión (Tabla 3). 
Tabla 3. Propuesta de descripción de lesiones musculares deportivas.

\begin{tabular}{|c|c|c|c|c|c|c|}
\hline $\begin{array}{l}\text { Tipo de } \\
\text { lesión }\end{array}$ & Ubicación & Fascia & Definición & Hematoma & Ultrasonido & $\begin{array}{l}\text { Resonancia } \\
\text { Magnética }\end{array}$ \\
\hline $\begin{array}{l}\text { Desgarro } \\
\text { Fibrilar }\end{array}$ & $\begin{array}{l}\text { Central o } \\
\text { periférico. }\end{array}$ & $\begin{array}{l}\text { No } \\
\text { compromete } \\
\text { la fascia. }\end{array}$ & $\begin{array}{l}\text { Compromete fibras } \\
\text { musculares } \\
\text { (microscópico). } \\
\text { No hay "defecto" } \\
\text { intramuscular. }\end{array}$ & $\begin{array}{l}\text { No hay colección } \\
\text { líquida detectable. } \\
\text { Edema y/o } \\
\text { hemorragia focal. }\end{array}$ & $\begin{array}{l}\text { Aumento o disminución } \\
\text { focal de la ecogenicidad. } \\
\text { Distorsión de la } \\
\text { arquitectura } \\
\text { peniforme. }\end{array}$ & $\begin{array}{l}\text { Aumento focal de } \\
\text { señal en secuencias } \\
\text { sensibles a líquido. }\end{array}$ \\
\hline \multirow[t]{3}{*}{$\begin{array}{l}\text { Desgarro } \\
\text { Fascicular }\end{array}$} & $\begin{array}{l}\text { Central } \\
\text { (miotendíneo } \\
\text { o músculo- } \\
\text { aponeurótico } \\
\text { central). }\end{array}$ & $\begin{array}{l}\text { No } \\
\text { compromete } \\
\text { la fascia. }\end{array}$ & $\begin{array}{l}\text { Compromete fascículos } \\
\text { (macroscópico) } \\
\text { Hay "defecto" } \\
\text { intramuscular en } \\
\text { uniones } \\
\text { mioaponeuróticas } \\
\text { centrales. }\end{array}$ & $\begin{array}{l}\text { Hematoma } \\
\text { intramuscular. }\end{array}$ & $\begin{array}{l}\text { Defecto intramuscular, } \\
\text { asociado a distorsión } \\
\text { de la arquitectura, } \\
\text { con colección } \\
\text { líquida/hematoma. }\end{array}$ & $\begin{array}{l}\text { Colección líquida } \\
\text { intramuscular mio- } \\
\text { aponeurótica central. } \\
\text { Edema muscular. }\end{array}$ \\
\hline & \multirow[t]{2}{*}{$\begin{array}{l}\text { Periférico } \\
\text { (miofascial } \\
\text { periférico). }\end{array}$} & $\begin{array}{l}\text { Sin } \\
\text { rotura de } \\
\text { la fascia. }\end{array}$ & $\begin{array}{l}\text { Compromete fascículos } \\
\text { (macroscópico) } \\
\text { Hay "defecto" en } \\
\text { uniones miofasciales } \\
\text { periféricas } \\
\text { sin rotura de la fascia. }\end{array}$ & $\begin{array}{l}\text { Hematoma } \\
\text { intramuscular } \\
\text { periférico por } \\
\text { dentro } \\
\text { de la fascia. }\end{array}$ & $\begin{array}{l}\text { Defecto intramuscular } \\
\text { con colección líquida } \\
\text { en la periferia del } \\
\text { músculo, subfascial. }\end{array}$ & $\begin{array}{l}\text { Colección líquida } \\
\text { subfascial. } \\
\text { Edema muscular. }\end{array}$ \\
\hline & & $\begin{array}{l}\text { Con rotura } \\
\text { de la } \\
\text { fascia. }\end{array}$ & $\begin{array}{l}\text { Compromete fascículos. } \\
\text { (macroscópico) } \\
\text { Hay "defecto" en } \\
\text { uniones miofasciales } \\
\text { periféricas con } \\
\text { rotura de la fascia. }\end{array}$ & $\begin{array}{l}\text { Hematoma } \\
\text { intermuscular y/o } \\
\text { subcutáneo } \\
\text { (equimosis). }\end{array}$ & $\begin{array}{l}\text { Defecto intramuscular } \\
\text { miofascial periférico. } \\
\text { Colección líquida } \\
\text { intermuscular. }\end{array}$ & $\begin{array}{l}\text { Colección líquida } \\
\text { periférica } \\
\text { comunicada con } \\
\text { espacio intermuscular } \\
\text { y/o subcutáneo. } \\
\text { Edema muscular. }\end{array}$ \\
\hline $\begin{array}{l}\text { Desgarro } \\
\text { subtotal }\end{array}$ & $\begin{array}{l}\text { Grandes } \\
\text { grupos } \\
\text { musculares } \\
\text { como } \\
\text { isquiotibiales } \\
\text { o cuádriceps. }\end{array}$ & $\begin{array}{l}\text { Generalmente } \\
\text { hay } \\
\text { rotura de la } \\
\text { fascia. }\end{array}$ & $\begin{array}{l}\text { Rotura de más del } \\
50 \% \text { del vientre } \\
\text { muscular en el eje corto. }\end{array}$ & $\begin{array}{l}\text { Gran hematoma } \\
\text { interpuesto en el } \\
\text { defecto muscular. }\end{array}$ & $\begin{array}{l}\text { Gran colección líquida } \\
\text { interpuesta en el "gap" } \\
\text { o defecto del vientre } \\
\text { muscular. }\end{array}$ & $\begin{array}{l}\text { Colección líquida, } \\
\text { defecto o rotura de } \\
\text { fibras con retracción } \\
\text { de cabos. } \\
\text { Edema muscular. }\end{array}$ \\
\hline $\begin{array}{l}\text { Desgarro } \\
\text { total }\end{array}$ & $\begin{array}{l}\text { Grandes } \\
\text { grupos } \\
\text { musculares } \\
\text { como } \\
\text { isquiotibiales } \\
\text { o cuádriceps. }\end{array}$ & $\begin{array}{l}\text { Siempre hay } \\
\text { rotura de la } \\
\text { fascia. }\end{array}$ & $\begin{array}{l}\text { Rotura completa del } \\
\text { vientre muscular. } \\
\text { Se incluye avulsión } \\
\text { completa de la } \\
\text { inserción. }\end{array}$ & $\begin{array}{l}\text { Gran hematoma } \\
\text { interpuesto en el } \\
\text { defecto muscular } \\
\text { y plano } \\
\text { intermuscular } \\
\text { y/o subcutáneo. }\end{array}$ & $\begin{array}{l}\text { Defecto intramuscular } \\
\text { con retracción de cabos } \\
\text { y colección interpuesta } \\
\text { en la zona de rotura. }\end{array}$ & $\begin{array}{l}\text { Colección líquida. } \\
\text { Defecto que } \\
\text { compromete todo } \\
\text { el vientre muscular. } \\
\text { Retracción de cabos. }\end{array}$ \\
\hline $\begin{array}{l}\text { Contusión } \\
\text { Laceración }\end{array}$ & $\begin{array}{l}\text { Generalmente } \\
\text { extremidad } \\
\text { inferior. Muslo } \\
\text { más frecuente } \\
\text { Generalmente } \\
\text { más de un } \\
\text { músculo } \\
\text { comprometido }\end{array}$ & $\begin{array}{l}\text { Contusión: } \\
\text { generalmente } \\
\text { no } \\
\text { compromete } \\
\text { la fascia. } \\
\text { Laceración: } \\
\text { Siempre } \\
\text { hay rotura } \\
\text { de la fascia. }\end{array}$ & $\begin{array}{l}\text { Desde foco de } \\
\text { edema/hemorragia } \\
\text { hasta rotura subtotal o } \\
\text { total. }\end{array}$ & $\begin{array}{l}\text { Depende de la } \\
\text { envergadura de } \\
\text { la lesión. } \\
\text { Desde edema } \\
\text { focal a gran } \\
\text { colección líquida } \\
\text { intramuscular } \\
\text { y eventualmente } \\
\text { interfascial- } \\
\text { subcutánea. }\end{array}$ & $\begin{array}{l}\text { Desde edema focal a } \\
\text { a gran colección } \\
\text { líquida intramuscular. } \\
\text { Aumento de } \\
\text { ecogenicidad. } \\
\text { Distorsión de la } \\
\text { arquitectura. }\end{array}$ & $\begin{array}{l}\text { Edema. } \\
\text { Defecto } \\
\text { intramuscular. } \\
\text { Colección líquida } \\
\text { intramuscular. } \\
\text { Eventualmente } \\
\text { retracción de } \\
\text { cabos. }\end{array}$ \\
\hline
\end{tabular}




\section{Evolución de las lesiones}

Parte del rol de la imagenología es monitorear la evolución de los desgarros y detectar eventuales complicaciones ${ }^{6,19}$, en nuestro medio lo realizamos especialmente con US.

- En los desgarros fibrilares buscamos la resolución del edema o hemorragia comparando las dimensiones del área comprometida. Estas lesiones reparan generalmente ad integrum.

- En los desgarros fasciculares, el hematoma va cambiando progresivamente. Se va "rellenando" la cavidad con tejido hipoecogénico desde la periferia al centro.

La información relevante para el clínico es la presencia de hematoma líquido residual y edema de las fibras musculares, en etapas más tardías la aparición de cicatriz.

- En los desgarros totales, subtotales y avulsiones tendíneas también evaluamos la regresión del hematoma, que en general demora más que en las lesiones anteriores, siendo estas lesiones las de más lenta recuperación y peor pronóstico.

\section{Fisiopatología de la reparación}

Las lesiones musculares son generalmente autolimitadas. Para realizar una correcta interpretación de los hallazgos en imágenes es importante que además de la anatomía, conozcamos la fisiopatología de estas lesiones. En una lesión aguda hay destrucción de fibras seguida de necrosis, inflamación local y formación de hematoma. Luego el área necrótica es invadida por pequeños vasos sanguíneos, células mononucleares, macrófagos y linfocitos $T$ que infiltran localmente. Estos secretan citoquinas y factores de crecimiento. Las lesiones que afectan los tejidos blandos del sistema músculo esquelético se resuelven por un mecanismo principalmente de reparación, a diferencia de lesiones óseas que curan por regeneración.

El modelo de curación de lesiones musculares incluye 3 fases bien diferenciadas, que dura aproximadamente 3 semanas ${ }^{17,18}$.

1. Fase de destrucción: En los primeros días hay degeneración e inflamación activa. En este período se produce la ruptura del tejido muscular y la necrosis de las miofibrillas con la formación de un hematoma entre las fibras rotas. Además, se produce una reacción celular inflamatoria.

2. Fase de reparación: donde se produce la reabsorción del tejido necrotizado, la regeneración de las miofibrillas y la producción de un área de tejido conjuntivo y de nuevos vasos capilares. La regeneración usualmente comienza entre los 7 y 10 días. El peak de la regeneración es a las dos semanas y disminuye en la tercera y cuarta.

3. Fase de remodelación: se realiza la maduración de las nuevas miofibrillas recién formadas y la reorganización del tejido que va a permitir recuperar la capacidad contráctil del nuevo músculo. La formación de una cicatriz (fibrosis) comienza entre la segunda y tercera semana, y la cicatriz va aumentado de tamaño con el tiempo.

Habitualmente las fases 2 y 3 se solapan en el tiempo (Figura 15).

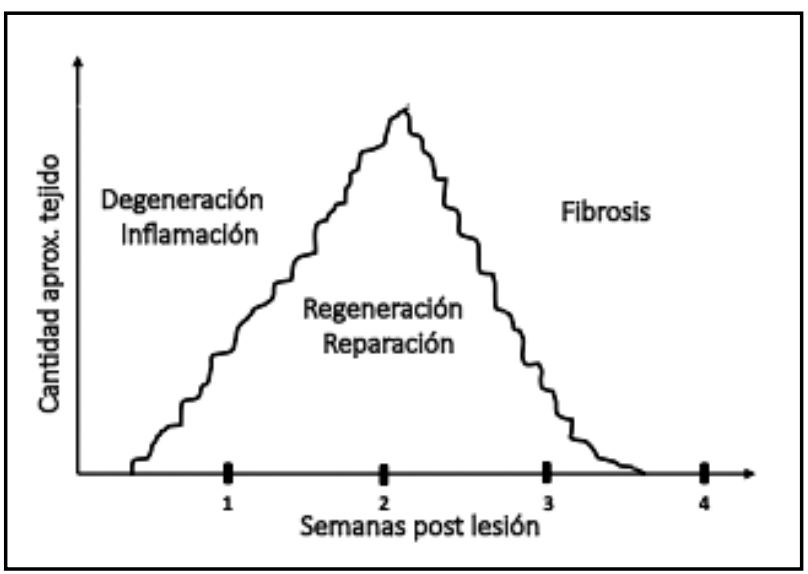

Figura 15. Gráfico de la reparación muscular.

\section{Complicaciones \\ Cicatriz muscular}

Todas las lesiones musculares macroscópicas curan con fibrosis en mayor o menor grado. Cuando las lesiones no son tratadas adecuadamente, el resultado es una cicatriz fibrosa-retráctil que constituye una complicación, determinando nuevas zonas de transición anatómicas que predisponen a re-desgarros ${ }^{19}$.

Cuando el tratamiento es precoz y adecuado, puede lograrse mayor grado de regeneración versus cicatrización y el resultado será menor fibrosis.

Tanto en US como en RM puede observarse una imagen estrellada, retráctil, asociada a disminución de volumen y atrofia muscular en las fibras vecinas a la cicatriz.

\section{Hernia muscular}

Constituye una posible complicación de desgarros que han comprometido la fascia. Se define como la protrusión de una parte del músculo a través de un defecto fascial. La mayoría son asintomáticas, aunque a veces pueden causar dolor o edema en la zona de la hernia. La mejor herramienta de estudio por imágenes es el US en reposo y dinámico, donde es posible demostrar el tamaño del defecto de la fascia y la porción de músculo extruído ${ }^{20}$.

\section{Otras}

Otras complicaciones que se pueden presentar son síndrome compartamental crónico y calcificaciones-miositis osificante ${ }^{21,22,23}$. 


\section{Conclusión}

Las lesiones musculares deportivas son muy frecuentes. El rol de las imágenes es fundamental en el diagnóstico y seguimiento. EI US y la RM son los exámenes de elección, la decisión de cual utilizar debería considerar la experiencia del radiólogo y la disponibilidad del equipamiento apropiado.

El radiólogo debe conocer la anatomía individual de cada músculo y los antecedentes clínicos para la adecuada interpretación de los hallazgos imagenológicos.

Existen múltiples clasificaciones de lesiones musculares deportivas, la gran mayoría en grados, basadas principalmente en RM.

En este artículo proponemos una nomenclatura y descripción, basada principalmente en la anatomía muscular, la localización y el tipo de lesión, útil tanto para US como para RM. Se espera con ello uniformar criterios diagnósticos y mejorar el manejo de estas lesiones.

\section{Referencias}

1. Jiménez JF. Lesiones musculares en el deporte. Revista Internacional de Ciencias del Deporte 2006; 3: 55-67.

2. Exeter D., Connell D. Skeletal Muscle: Functional Anatomy and Pathophysiology. Semin Musculoskelet Radiol 2010; 14: 97-105.

3. Huard J, Li Y, Fu F. Muscle Injuries and Repair: Current Trends in Research. J Bone Joint Surg Am 2002; 84: 822-832.

4. Zamorani MP., Valle M. Muscle and Tendon. In: Bianchi S, Martinoli C. Ultrasound of the Musculoskeletal System. 1st edition. Germany. Springer-Verlag Berlin Heidelberg 2007; 45-96.

5. Lee J., Healy J. Sonography of muscle injury. In: Allan P, Baxter G, Weston M. Clinical Ultrasound, 3rd Edition. United Kingdom. Elsevier 2011; 1137-1157.

6. El-Khoury G, Brandser EA, Kathol MH, Tearse DS, Callaghan JJ. Imaging of muscle injuries. Skeletal Radiol 1996; 25: 3-11.

7. Muñoz S. Lesiones musculares deportivas: Diagnóstico por imágenes. Rev Chil Radiol 2002; 8: 127-132.

8. Douis H., Gillett M., James S. Imaging in the Diagnosis, Prognostication, and Management of Lower Limb Muscle
Injury. Semin Musculoskelet Radiol 2011; 15: 27-41.

9. Garrett W., Safran M., Seaber A., Glisson R., Ribbeck B. Biomechanical comparison of stimulated and nonstimulated skeletal muscle pulled to failure. Am J Sports Med 1987; 15: 448-454.

10. Mueller-Wohlfahrt H-W, Haensel L, Mithoefer K, Ekstrand J, English B, McNally S, et al. Terminology and classification of muscle injuries in sport: The Munich consensus statement. Br J Sports Med 2012; 0: 1-9.

11. Pedret C, Balius R. Lesiones musculares en el deporte. Actualización de un artículo del Dr. Cabot, publicado en Apuntes de Medicina Deportiva en 1965. Apunts Med Esport 2015; 50: 111-120.

12. Lee JC., Healy J. Sonography of Lower Limb Muscle Injury. AJR 2004; 182: 341-351.

13. Shelly M., Hodnett P., MacMahon P., Moynagh M., MDa., Kavanagh E., Eustace S. MR Imaging of Muscle Injury. Magn Reson Imaging Clin N Am 2009; 17: 757-773.

14. Fleckenstein J., Weatherall P., Parkey R., Payne J., Peshock R. Sports-related Muscle Injuries: Evaluation with MR Imaging. Radiology 1989; 172: 793-798.

15. Pollock N., James S., Lee J., Chakraverty R. British athletics muscle injury classification: A new grading system. Br J Sports Med 2014; 48: 347-1351.

16. Evans G., Haller R., Wyrick P., Parkey R., Fleckenstein J. Submaximal Delayed-Onset Muscle Soreness: Correlations between MR Imaging Findings and Clinical Measures. Radiology 1998; 208: 815-820.

17. Järvinen TA., Järvinen TL., Kääriäinen M., Kalimo K., Järvinen M. Muscle Injuries. Biology and Treatment. Am J Sports Med 2003; 33: 745-764.

18. Järvinen TA., Järvinen M., Kalimo K. Regeneration of injured skeletal muscle after the injury. Muscles Ligaments Tendons J 2013; 3: 337-345.

19. Woodhouse J., FRCR., McNally E. Ultrasound of Skeletal Muscle Injury: An Update. Semin Ultrasound CT MRI 2011; 32: 91-100.

20. Beggs I. Sonography of Muscle Hernias. AJR 2003; 180: 395-399.

21. Boutin R., Fritz R., MDb., Steinbach L. Imaging of sportsrelated muscle injuries. Magn Reson Imaging Clin N Am 2003; 11: 341-371.

22. Counsel P., Breidahl W. Muscle Injuries of the Lower Leg. Semin Musculoskelet Radiol 2010; 14: 162-175.

23. Koh E., McNally E. Ultrasound of Skeletal Muscle Injury. Semin Musculoskelet Radiol 2007; 11: 162-173. 